\title{
O Sentido (Conceito) de Liberdade na Teoria do Discurso de Ernesto Laclau
}

\author{
Felipe Corral de Freitas \\ Universidade Federal de Pelotas
}

\section{Introdução ${ }^{1}$}

De origem marxista, a teoria do discurso de Ernesto Laclau tem como objetivos ampliar e redefinir a compreensão da atividade política, bem como redimensionar as relações de conflitos que configuram as relações sociais/políticas para além da polarização entre proletariado e burguês. Sem abandonar o marxismo como ponto de partida teórico e de reflexão, Laclau aposta na redefinição de seus conceitos.

Influenciado pelo pós-estruturalismo, Laclau entende que não existe nenhum fundamento capaz de definir a estruturalidade última de uma identidade política. As identidades são constituídas por atos de identificações que só são possíveis pelo fato de que nenhuma identidade assume uma positividade final, ou um fundamento último. Ao contrário, é o caráter deslocado de toda identidade que permite esses processos de identificações e a constituição da pluralidade do social. É neste sentido que o autor desconstrói determinadas categorias marxistas apresentando que as identidades de proletariado e burguês não podem assumir uma positividade fundante ou última.

Laclau desconstrói o entendimento de emancipação segundo a teoria marxista e desenvolve uma perspectiva de liberdade mais complexa e menos restritiva em termos de teoria política. Segundo a visão clássica do marxismo, em linhas gerais liberdade seria o momento da emancipação do proletariado em relação a sua condição de existência imposta pela burguesia que era a detentora dos meios materiais de produção, bem como produtora da compreensão da realidade social/política. Ou seja, liberdade, neste sentido, seria a emancipação do proletariado em relação à dominação material e ideológica da burguesia. Deste modo, o entendimento de liberdade proposto pela teoria do discurso laclauniana parte de uma crítica realizada ao reducionismo identitário contido na teoria marxista, bem como aponta novos caminhos interpretativos quanto ao conceito e seus desdobramentos em relação à teoria política e sociológica. Duas contribuições podem ser destacadas. A primeira é a forma de compreender o social como um espaço simbolicamente construído por discursos concorrentes e, por consequência, estabelecido a partir de relações políticas. A segunda é a forma como o autor (e Mouffe) trabalha o "movimento" entre a desestruturação de uma estrutura (ou ordem) e sua reestruturação. Essas duas contribuições estão relacionadas diretamente com o sentido de liberdade desenvolvido pelo autor, uma liberdade que emerge a partir de relações políticas em seus processos contínuos de estruturação, desestruturação e reestruturação, evocando um caráter libertador e escravizante nesse movimento.

O objetivo deste artigo consiste em pensar o que constitui liberdade, seu lugar e seu momento a partir da teoria do discurso de Ernesto Laclau. O recorte realizado em torno do conceito de liberdade

\footnotetext{
1 Agradeço os pareceristas anônimos da Revista Sul-Americana de Ciência Política por suas contribuições. Evidentemente, continuo como único responsável pelas falhas e omissões.
} 
em Laclau foi centrado nas obras Hegemonia e Estratégia Socialista: por uma política democrática radical (2015 [1985]), Novas Reflexões sobre a Revolução do Nosso Tempo (2000 [1990]) e, especialmente, Emancipação e Diferença (2013 [1996]). Em termos analíticos, busca-se realizar um contraste entre esta concepção de liberdade e aquela que se encontra de maneira mais recorrente na teoria marxista. Em se tratando de uma ampliada e renovada percepção de liberdade, bem como não fundacional e não estruturante em relação às formações de identidades (processos de identificação política), defende-se que a interpretação sobre liberdade desenvolvida por Laclau abre novas possibilidades teóricas em relação aos modelos de democracia, pois compreende novas possibilidades de processos de formações de identidades/identificações.

Para isso, este trabalho está dividido em cinco seções. Na primeira seção serão apresentados os conceitos da teoria do discurso, os quais servirão para a compreensão da noção (conceito) de liberdade segundo o autor. Na segunda seção o foco será a apresentação dos elementos teóricos do pósfundacionismo e do pós-estruturalismo contidos na teoria do discurso de Ernesto Laclau. Na terceira seção serão apresentadas as bases originárias da teoria do discurso laclauniana a partir da crítica ao marxismo e seu entendimento de emancipação; sua impossibilidade. Na quarta seção serão apresentados os conceitos de deslocamento e antagonismo, imprescindíveis para a compreensão do que o autor entende por liberdade. Após fazer esta organização, na quinta e última seção será apresentado o conceito de liberdade segundo Laclau.

\section{Os conceitos da teoria do discurso de Laclau}

Para Laclau e Mouffe (2015 [1985], p. 180), todo objeto é uma formação discursiva em que nenhuma significação pode ser constituída fora disso, ou seja, todo objeto é constituído do social, que por sua vez é discursivo. Sendo assim, o social é necessariamente um social simbólico, discursivo, e fundado a partir da relação política. Conforme os próprios autores:

a) $\mathrm{O}$ fato de que todo objeto é constituído como objeto de discurso não tem nada a ver com a existência de um mundo externo ao pensamento, nem com a oposição realismo/idealismo. Um terremoto ou queda de um tijolo é um evento que certamente existe, no sentido de que ocorre aqui e agora, independente de minha vontade. Mas, se sua especificidade como objeto será construída seja em termos de um fenômeno natural ou como expressão da ira de Deus, vai depender da estruturação de um campo discursivo. $O$ que se nega não é que tais objetos existam externamente ao pensamento, mas antes a afirmação bastante diferente de que eles próprios possam se constituir como objetos fora de qualquer condição discursiva de emergência.

b) $\mathrm{Na}$ origem do preconceito anterior reside a suposição do caráter mental do discurso. Contra isso, afirmamos o caráter material de toda estrutura discursiva [...]. Os elementos linguísticos e não-linguísticos não são meramente justapostos, mas constituem um sistema diferencial e estruturado de posições - isto é, um discurso. As posições diferenciais incluem, portanto, uma dispersão dos diversos elementos materiais (Laclau e Mouffe, 2015 [1985], p. 181-182).

Um discurso é uma prática articulatória e significativa que constitui e organiza relações sociais, como apresentada no exemplo do excerto acima. O linguístico não pode ser visto separado do social, 
rechaçando toda e qualquer separação entre práticas discursivas e práticas não discursivas, pois o discurso não possui um caráter meramente mental, mas sim material. Com isso, existe uma relação entre a fala (o linguístico) e o que ela significa (a materialidade do discurso - seu significado), formando uma totalidade significativa. Neste sentido, o discurso é mais do que a união entre gesto e fala, ele é uma relação de significação (Mendonça, 2007, p. 250).

Discurso, deste modo, é entendido a partir de um conjunto de elementos em que as relações desempenham um papel constitutivo na sua simbolização; "Isso significa que os elementos não preexistem ao complexo relacional, mas se constituem através dele" (Laclau, 2013 [2005], p. 116). Isso quer dizer que um discurso não se fundamenta em si mesmo. Quer dizer também que sua existência é precária e contingente, ou seja, resultado de um processo hegemônico que sedimento uma determinada verdade e não outra. Portanto, não existe nada que ultrapasse o jogo das diferenças assumindo um caráter de fundamento anterior ao próprio jogo, nem mesmo a fundação de uma verdade eterna.

O campo da discursividade é o espaço onde diversas formações discursivas entram em concorrência umas com as outras, e formam um jogo de equilíbrio instável. Um discurso se forma sempre na tentativa de dominar esse campo, buscando se constituir como um ponto nodal, um ponto hegemônico (Laclau e Mouffe, 2015 [1985], p. 187). Sendo assim, todo discurso é fruto de uma relação articulatória que fixa sentidos precários e contingentes a partir de um ponto nodal, que nada mais é que um ponto sistematizador das diferenças relacionadas a partir de seu corte antagônico. Para os autores, "é suficiente que certas regularidades estabeleçam posições diferenciais para que possamos falar de uma formação discursiva" (Laclau e Mouffe, 2015 [1985], p. 182).

No momento da articulação, tanto a lógica da equivalência como a lógica da diferença operam. No caso da lógica da diferença, sua principal característica perpassa o entendimento de que esse momento diferencial não impede sua articulação com outro elemento. É o fato de existir o "diferencial" que torna tal articulação possível; o diferencial nada mais é que a particularidade de um elemento mantida em sua transição para o status de momento de uma cadeia articulatória. Já a noção de lógica da equivalência demonstra a similaridade de determinado aspecto no momento articulatório. Dentro do campo discursivo, é a lógica da equivalência que forma a articulação de elementos que passaram a ser considerados momentos dessa cadeia articulatória. É importante deixar claro que a equivalência representada no status de momento não elimina a diferença do status de elemento.

A relação entre os conceitos de diferença e equivalência abre caminho teórico para compreender como processos de formações de identidades nunca são completos e finitos. Uma identidade só se torna identidade por manter seu status diferencial. Isso quer dizer que a equivalência entre dois termos no processo de formação de uma identidade nunca apagará as diferenças constituidoras desses termos. Dito de outra forma, o processo articulatório entre identidades precárias e contingentes na construção de renovadas identidades nunca será completo em virtude da manutenção de suas diferenças. Caso contrário, constituiriam uma mesma identidade (Laclau e Mouffe, 2015 [1985], p. 206-207). Nos contextos sócio-políticos após a Segunda Guerra Mundial e principalmente após a queda do Muro de Berlim esse processo ajuda a explicar a emergência de novas identidades com novas demandas articuladas, como, por exemplo, as disputas religiosas no Leste Europeu e as ampliadas efervescências políticas/sociais por reconhecimento de grupos excluídos, como o movimento LGBT.

Stavrakakis (2007 [1999]) apresenta a diferença entre identidade e identificação, enfatizando o caráter constitutivo da identificação política a partir de sua impossibilidade de completude, tendo em 
vista a ideia de falta constitutiva ${ }^{2}$. Assim, o resultado de uma identificação jamais resultará numa identidade final, mas numa identificação que "sedimentará" uma identidade formada pelas suas articulações precárias e contingentes; uma formação discursiva sempre marcada por uma falta. É neste tocante que entendemos que para haver identificações políticas é necessário perceber que o espaço do social é marcado por uma gama de antagonismos que indicam seu caráter fragmentado e plural. Portanto, todo ato de identificação política na construção de identidades necessita do corte antagônico, do seu limite e, por isso, do seu exterior constitutivo ${ }^{3}$, como a possibilidade do momento da articulação interna de um discurso na construção de sua positividade - sempre limitada e falha.

Nesse processo, o antagonismo é o momento que marca a ruptura do social e o momento que possibilita a instituição do político, marcado pelo deslocamento - ele abre caminho para as relações políticas propriamente ditas e para os processos de identificação. Deste modo, a articulação discursiva, para existir, precisa de um exterior constitutivo, e esse exterior constitutivo é a marca do antagonismo, é o discurso antagônico. Isso significa que a relação antagônica dá início à construção de identidades políticas a partir de uma relação com o "Outro" e com o próprio discurso interno - os momentos articulados ${ }^{4}$. Os conceitos de antagonismo e deslocamento serão retomados em uma seção específica.

É através do ponto nodal ${ }^{5}$ que se estabelece a união entre os momentos diferenciais, uma vez que um ponto nodal, ou seja, um ponto discursivo privilegiado, aglutina outros discursos em torno de si. O ponto nodal, antagonicamente construído em relação a outro discurso (outro ponto nodal), é ainda o determinante dos limites desse discurso, do que está articulado e do que não está articulado, ou seja, o que ele representa e o que não representa. O ponto nodal é o resultado da organização de elementos que, posteriormente, se tornaram momentos de cadeia de equivalência e, por fim, se constitui como discurso; é o movimento pelo qual a lógica da equivalência irá subverter, em partes, todas as diferenças das identidades articuladas com esse ponto privilegiado. Mendonça (2003a, p. 143) esclarece que os pontos nodais diferenciam uma formação discursiva de outros discursos e também o diferencia dos elementos que não estão discursivamente articulados no campo da discursividade. Portanto, o ponto nodal, através da prática articulatória, é a possibilidade de uma determinada particularidade ter a sua universalização, ou seja, ter os seus sentidos hegemonizados.

\footnotetext{
${ }^{2}$ O conceito de falta constitutiva, apropriado por Laclau (2000 [1990]) e Stavrakakis (2007 [1999]), vem da psicanálise lacaniana e remete ao ingresso do sujeito no mundo simbólico a partir da separação entre a mãe e o filho, tendo no pai, metaforicamente, a representação desse processo de separação dos corpos da mãe e do filho. Esse processo, segundo Lacan (2008 [1973], p. 208-210), gera um trauma que, por sua vez, é traduzido como uma falta que constituirá todos os processos de individualização e socialização do sujeito. Por esse motivo, tanto Laclau como Stavrakakis não concebem o processo de identificação como um meio para se atingir uma identidade final.

${ }^{3}$ O conceito de exterior constitutivo, desenvolvido por Derrida (2014 [1971]), é apropriado por Laclau e Mouffe (2015 [1985]) para explicar o processo pelo qual os antagonismos emergem e articulam sentidos contrários em seus processos constituidores.

${ }^{4}$ Em trabalho paralelo ao de Laclau e como complemento teórico (sobre essa "divisão", ver Mendonça (2010, p. 479480)), Mouffe (1999 [1996]; 2003 [2000]; 2005; 2013; 2015 [2005]) reinterpreta a noção de "antagonismo" em Schmitt (2009 [1932]) e a divisão entre "amigo" e "inimigo", promovendo uma separação entre "o político" e "a política", em que "o político", entendido a partir de uma dimensão ontológica, é caracterizado pelo antagonismo "inerente às relações humanas, um antagonismo que pode tomar muitas formas e emergir em diferentes tipos de relações sociais" (Mouffe, 2005, p. 20), ou seja, no ôntico, na política. A política, de outra forma, designa a institucionalidade e o conjunto de práticas que buscam estabelecer certa ordem ao social; práticas essas que tem por objetivo "acalmar" os possíveis antagonismos. Para mais informações sobre esta apropriação teórica, ver Martínez (2014).

5 A noção de ponto nodal é oriunda da psicanálise lacaniana, que quer dizer "point de capiton” (Lalcau e Mouffe, 2015 [1985], p. 187).
} 
Com isso, as práticas articulatórias são constituídas em torno de pontos nodais e, ao mesmo tempo, suas constituidoras.

Todo discurso busca se hegemonizar, ou seja, uma identidade tenta impor sua particularidade sobre a outra, mesmo que seu sentido nunca seja plenamente constituído; e é disso que decorre a impossibilidade de totalização, a impossibilidade da formação de um discurso pleno. Todo instante hegemônico necessita de uma relação antagônica, pois, o momento em que uma identidade particular se torna hegemônica é precedido por algum discurso que o antagonizava ou ainda se mantém como antagônico. Por outro lado, mesmo que haja uma hegemonia, o social ainda se mantém fragmentado por diversas lutas antagônicas, o que poderá ameaçar a hegemonia "dominante". "[...] a hegemonia emirja num campo atravessado por antagonismo e, portanto, supunha os fenômenos da equivalência e os de fronteira. Porém, inversamente, nem todo antagonismo supõe práticas hegemônicas" (Laclau e Mouffe, 2015 [1985], p. 215).

Um discurso hegemônico é um discurso sistematizador, pois ele aglutina outros sentidos, ou seja, hegemonia é quando uma identidade, de forma precária e contingente, passa a representar diversas outras identidades dentro desse discurso. Com isso, o discurso sistematizador acaba abarcando novos sentidos, o que faz com que seu conteúdo original seja modificado, pois, para buscar essa hegemonia, ele tem de ampliar seus conteúdos. Portanto, são através dessas disputas hegemônicas que se constituem os discursos políticos, ou seja, a hegemonia parte de qualquer relação de luta política (Laclau e Mouffe, 2015 [1985], p. 219).

Outro conceito de grande importância para a teoria do discurso é a noção de significante vazio. Segundo Laclau, "um significante vazio é, no sentido estrito do termo, um significante sem significado" (Laclau, 2011 [1996], p. 67). Para Mendonça (2003b, p. 67), um significante vazio é um significante sem significado em função de uma polissemia de sentidos que estão articulados em torno de seu significado. Segundo o autor, isso faz com que este esvazie seus conteúdos específicos na busca de representar tantas outras identidades, tornando-se, portanto, um significante sem um significado específico. Com isso, ele representa muitas outras identidades, mas nenhuma única em particular, e assim se torna um significante vazio. Tal vazio é entendido a partir de uma abundância de sentidos, e não pela ausência deles.

É nesse sentido que para Laclau (2011 [1996], p. 75) o significante pode estar vinculado a distintos significados. Isto significa que demandas diferentes, com sentidos diferentes, se articulam em torno de um ponto nodal, um ponto que teve a sua particularidade universalizada, portanto, tornando-se um significante vazio. Segundo Laclau, o significante vazio, uma diferença particular que assumiu o papel de representação - sem deixar de ter sua particularidade - representa todas as identidades particulares que estão articuladas com esse significante. Por exemplo, as "Diretas Já!", um movimento civil ocorrido no Brasil entre os anos de 1983 e 1984 em que eram reivindicadas eleições diretas para presidente, assumiu a posição de ponto nodal e de significante vazio em que representava, entre outras questões, demandas ligas aos sindicatos, ao movimento feminista, a entidades religiosas e ao movimento estudantil (Mendonça, 2007, p. 244).

A existência de forças antagônicas e a instabilidade das fronteiras entre elas, que constitui a relação entre equivalência e limite, são marcadas pela relação de flutuação entre elementos que aparecem nesses discursos ainda em formação, o que possibilita a construção de uma hegemonia. Portanto, a formação de pontos nodais e a construção de uma relação hegemônica só são possíveis 
tendo em vista o fato de que todo significado é vazio, dependendo da relação de formação desse significado. Logo, por meios desses processos são construídos os discursos.

\section{0 pós-estruturalismo na teoria do discurso de Laclau: elementos teóricos atuais}

Influenciado pelo pós-estruturalismo a partir de autores como Heidegger, Derrida e Lacan ${ }^{6}$, Laclau aponta os limites da teoria marxista no que se refere aos seus aspectos deterministas e fundantes. Tais elementos serviram de ponto de partida para uma grande reflexão sobre todos os conceitos que perpassam a teoria marxista, como ideologia, hegemonia, emancipação e, o que nos interessa nesse artigo, liberdade.

As bases ontológicas e epistemológicas do pós-estruturalismo denunciam a impossibilidade da existência de um fundamento último que estruture as relações e identidades, configurando a estruturalidade fundante de toda estrutura. É neste sentido que tal corrente se mostra crítica à tradição filosófica de caráter positivista e analítica e se inscreve numa epistemologia complexa ${ }^{7}$.

O pós-fundacionalismo, em que se sustenta o pós-estruturalismo, não deve ser entendido como um antifundacionalismo ou a partir de uma perspectiva pós-moderna em que tudo pode (Marchart, 2009 [2007], p. 14) ${ }^{8}$. Tanto o antifundacionalismo como o pós-fundacionalismo apresentam críticas em relação à ideia de que a sociedade pode ser compreendida a partir de determinadas estruturas invariáveis. No entanto, mesmo críticos ao fundacionalismo, o antifundacionalismo e o pósfundacionalismo apresentam diferenças importantes. $\mathrm{O}$ antifundacionalismo entende que não existe nenhum fundamento que estruture as relações sociais. Já o pós-fundacionalismo não tem a intenção de eliminar por completo a existência do fundamento, mas apresentar sua incapacidade de completude e seu caráter não essencialista. Portanto, o que está em jogo não é a eliminação de todos os fundamentos, mas apresentar a impossibilidade de um fundamento último 9 .

O que o pós-fundacionalismo apresenta é uma desconstrução das bases de sustentação do fundacionalismo, e não a sua mera inversão, uma das principais críticas aos antifundacionalistas. Portanto, o principal ponto aqui não é a negação de um fundamento e nem mesmo a sua total inexistência, pelo contrário, é partir do entendimento de que é impossível identificar um fundamento final; fundamentos que não contém um "fundo" e, por isso, fundamentos sempre contingentes (Mendonça, Linhares e Barros, 2016).

O elemento pós-fundacional contido nos escritos de Laclau pode ser atrelado à ideia de ausência de um fundamento como algo estruturante, ou seja, a falta de uma estrutura última possibilita a construção de uma estrutura precária e contingente. Tendo como base os escritos de Laclau, o poder se constitui num espaço vazio em que identidades são formadas a partir de discursos e originam novos discursos. Como esclarece Marchart (2009 [2007], p. 136), o espaço vazio em Laclau é a própria

\footnotetext{
${ }^{6}$ Outros autores, como Foucault (2013a [1969]; 2013b [1970]), por exemplo, também tiveram importância na estruturação da obra laclauniana. No entanto, entende-se que as principais bases da teoria do discurso de Ernesto Laclau podem ser atribuídas, além do próprio marxismo, a filosofia de Heidegger, a filosofia desconstrutivista de Derrida e a psicanálise Lacaniana (Mendonça e Rodrigues, 2014, p. 48).

${ }^{7}$ A teoria do discurso assume um caráter hermenêutico em sua complexidade.

${ }^{8}$ Como o objetivo aqui não é fazer um debate prolongado sobre estruturalismo e pós-estruturalismo, ver Williams (2012 [2005]).

${ }^{9}$ Para uma compreensão mais aprofundada sobre fundacionalismo e pós-fundacionalismo, ver Marchart (2009 [2007]).
} 
possibilidade de formação de identidades a partir de identificações oriundas de articulações que constituirão os discursos.

As bases pós-fundacionais podem ser percebidas nas críticas feitas pelos pós-estruturalistas ao estruturalismo, principalmente e originalmente a partir da desconstrução feita por Jacques Derrida (2014 [1971]). Para o estruturalismo a estrutura é compreendida como totalizante (Mendonça e Rodrigues, 2014, p. 36) a partir de um fundamento estruturante. De forma contrária, o pósestruturalismo identifica a impossibilidade dessa estrutura final; a impossibilidade de um fundamento último. Em Laclau, toda estrutura e todo fundamento nada mais são que hegemonias consolidadas a partir de lutas marcadas pelo antagonismo. Se, como afirmado, toda estrutura e fundamento são sedimentados a partir de lutas, também significa dizer que não são eternas, que podem ser substituídas por outra estrutura e por outro fundamento dependendo do contexto e das clivagens existentes no espaço do social. Isso quer dizer que o social é sempre fruto de lutas políticas. Quer dizer também que é a condição do político como conflito e antagonismo que subverte a ordem social e, no lugar, institui outra ordem, sempre precária e contingente. O social, assim, como ordem, é compreendido como a sedimentação de "algo" oriundo do político, do conflito, do antagonismo.

Com um debate fortemente consolidado dentro da teoria/filosofia social e política, o estruturalismo passou a ser questionado a partir da metade dos anos 1960. Baseado na crítica feita por Derrida em relação às bases do estruturalismo é possível classificar esse momento como o início do pós-estruturalismo. É importante perceber que o pós-estruturalismo se origina de dentro do estruturalismo, apresentando críticas e novas possibilidades de se pensar o social e o político a partir de seus próprios conceitos. Deste modo, o caminho desconstrutivista é entendido como uma crítica que parte de dentro do próprio estruturalismo, ou seja, não cabe pensar a partir de um antifundacionismo, mas perceber que nenhuma estrutura é capaz de contemplar todos os sentidos a ponto de garantir seu esgotamento.

No mesmo sentido do pós-fundacionalismo, o elemento pós-estruturalista da teoria do discurso é percebido a partir do caráter precário e contingente de toda estrutura. Isso significa dizer que estruturas são firmadas a partir de discursos sistematizadores que articulam em torno de seu momento representativo diferenças que jamais se tornarão um discurso puro. Dito de outra forma, uma falta jamais será contemplada de forma total, mas sempre parcial. Dizer isso implica a impossibilidade de completude de um discurso e de uma identidade, visto que a satisfação de uma falta não é garantia de seu fim, mas a possibilidade de novas faltas emergirem.

A teoria do discurso de Ernesto Laclau reconhece a precariedade e a contingência dos sentidos gerados a partir de um determinado discurso. As verdades são construídas discursivamente e podem mudar com o passar do tempo, ou seja, não há uma verdade para todo o sempre. Com isso, todos os sentidos devem ser entendidos dentro de seu contexto e a partir de suas condições de emergência.

Laclau (2000 [1990]) dá início a uma revisão sistemática de sua teoria, apresentando novos elementos explicativos. Após essa releitura, o autor reafirma que a negatividade é constitutiva de toda e qualquer identidade e, portanto, o projeto racionalista que busca determinar o sentido último, a verdade objetiva dos processos sociais, acaba destinado ao fracasso - tudo no social tem de ser compreendido em seu contexto. No sentido da negatividade, seu entendimento parte da afirmação de que uma identidade é tanto aquilo que ela abarca, quanto aquilo que ela exclui. Isso significa que um discurso se constitui a partir de uma relação antagônica imersa numa complexidade formada por diversas relações antagonizadas por diversos discursos, que são marcados por um vazio deslocatório. 
A possibilidade dessa relação e do não fechamento de um discurso e de uma identidade é marcada pela falta, pelo espaço vazio que possibilita a formação de novas identidades a partir de identificações políticas.

Toda relação de identificação necessita de algo externo, algo que coloque em xeque aquilo que antes definia uma estrutura qualquer, e é neste exato instante que se percebe a precariedade de tal estrutura e sua impossibilidade de fechamento. Por isso, a definição de identificação política contida no pensamento pós-fundacionalista e pós-estruturalista apresentada por Stavrakakis (2007 [1999], p. 31) nos permite entender a formação de uma identidade a partir de seu caráter deslocado, uma identidade sempre limitada, precária, contingente e falha. A relação com o outro é condição de qualquer identificação política (Laclau, 2000 [1990], p. 37) e, portanto, o limite antagônico marca as relações políticas constitutivas do social.

Se todo sentido é precário e, por isso, não existe uma verdade última e absoluta sobre qualquer questão desenvolvida no espaço do social, isso equivale a afirmar que não existe, em última instância, uma estrutura capaz de produzir um sentido final. Assim, a complexidade do social não pode ser compreendida por uma simples "análise" determinista; dito de outra forma, não existe um campo específico que poderá definir as possibilidades e os limites do conhecimento e, portanto, as verdades por ele produzidas.

Por esse motivo, Laclau (2000 [1990], p. 105) não fala em sociedade como um todo inteligível, mas em "espaço do social", fragmentado, em que o social se constitui na tentativa de construção desse objeto impossível, a sociedade. O não fundamento é a possibilidade de fixação de sentidos parciais, contingentes e precários, mas sempre necessários e desejados. Portanto, o social só pode ser compreendido a partir da articulação que o constitui, do discurso que fixa seu sentido, o que demonstra a impossibilidade da sociedade como um todo ou como uma parte fixada para todo o sempre.

\section{Do marxismo ao pós-marxismo: a impossibilidade da emancipação}

O debate teórico proposto por Laclau gira em torno dos principais conceitos da teoria marxista e suas interpretações em relação à atividade política e social. Laclau, por exemplo, desenvolveu uma leitura crítica em relação ao conceito de ideologia segundo a tradição marxista desde a publicação do livro "Política e Ideologia na Tradição Marxista" (Laclau, 1978 [1977]), e aprofundada em outras obras (Laclau e Mouffe, 2015 [1985]; Laclau, 2000 [1990], 2011 [1996]).

Oriundo da tradição marxista e vislumbrando novas leituras a partir dos trabalhos de Antonio Gramsci e Louis Althusser, como já identificado por Motta e Serra (2014), Laclau aposta numa releitura dos conceitos marxistas. Percebe-se que o projeto teórico marxista não contempla de forma satisfatória as diversas disputas que constituem o espaço do social, ficando restrita a simplificação identitária entre burguês e proletário; o projeto teórico marxista se mostrou incapaz de dar conta da compreensão das relações sociais contemporâneas (Mendonça, 2010, p. 481). É neste sentido que o autor entende que não existe somente um antagonismo social, mas sim vários, e o antagonismo capital versus trabalho é somente uma forma de antagonismo existente. Nos dias de hoje, por exemplo, lutas 
políticas emergem entorno de questões como o movimento ecológico e lutas urbanas contra a ocupação capitalista do espaço social (Laclau e Mouffe, 2015 [1985], p. 245) ${ }^{10}$.

A partir da crise do marxismo, a noção de hegemonia, desenvolvida por Gramsci e reinterpretada por Laclau, possibilita a compreensão da proliferação de novas contradições, além da já identificada por Marx e seus seguidores. É nesta linha de pensamento que se torna necessário pensar e entender as lutas sociais a partir de práticas articulatórias. Então, a fragmentação do espaço do social e a impossibilidade de determinação a priori das relações entres as identidades pulverizadas nesse espaço, marca o entendimento do que é apresentado como democracia radical. É neste campo da radicalidade da democracia que essas identidades se relacionam de forma mais autônomas, e ao se articularem modificam suas particularidades.

Segundo a visão marxista, o proletariado estaria imerso numa relação em que os donos dos meios de produção também eram os produtores das interpretações aceitas em relação à realidade social (Marx, Engels, 1998 [1846]). De forma simplificada, esta relação que separava os donos dos meios de produção e os trabalhadores afetava a vida dos trabalhadores de forma estrutural. Isso quer dizer que os trabalhadores eram excluídos da divisão da riqueza que por eles eram produzidas, bem como não questionavam sua posição em relação a essa cadeia. Neste ponto é que opera o papel da ideologia segunda a corrente clássica do marxismo, ideologia que era produzida pela classe dominante. Seria a superação deste fator ideológico que daria condições de os trabalhadores romperem com essa cadeia que os excluíam de grande parte das atividades sociais/políticas. Essa superação era entendida como emancipação; emancipação do proletariado em relação à classe burguesa. Neste sentido, emancipação assumiria um caráter de libertação total das estruturas sociais instituídas e "controladas" de forma ideológica e material pela burguesia. Emancipação, deste modo, seria a liberdade estrutural atingida pela classe trabalhadora. Portanto, emancipação e liberdade são tomadas como sinônimos.

Com base na obra Hegemonia e Estratégia Socialista (2015 [1985]), Laclau e Mouffe adotam uma linha crítica à teoria marxista, apresentando, assentada em seus próprios conceitos, seus limites e suas possibilidades a partir de uma releitura crítica. Com isso, no desenvolvimento da teoria do discurso, baseado nessa superação determinista, tal teoria se coloca, desta forma, em uma corrente teórica pós-marxista.

Os conceitos de ideologia, emancipação e liberdade, contidos na teoria marxista, são reinterpretados a partir das críticas realizadas por Laclau. A influência do pós-estruturalismo foi de grande relevância para essa desconstrução. A partir de agora será dada atenção a desconstrução feita por Laclau em relação ao conceito de emancipação, central para o entendimento de liberdade desenvolvido pelo autor.

Numa outra perspectiva, Laclau (2011 [1996]) afirma que emancipação é diferente de liberdade. Segundo o autor, se referindo à tradição clássica do marxismo, emancipação significaria o fim do poder, seria o momento de um vácuo permanente, no qual destituiu uma estrutura sem sedimentar, mesmo que de forma precária e contingente, outra. Laclau entende que todo ato emancipatório requer um momento de opressão, algo que tolhe o livre desenvolvimento de uma identidade. Isso de fato é percebido pela tradição clássica marxista. "Entre o momento emancipatório e a ordem social que o precedeu, há um abismo absoluto, uma radical descontinuidade" (Laclau, 2011 [1996], p. 23). Sendo

\footnotetext{
${ }^{10}$ Sobre esses aspectos, ver Laclau (1986).
} 
assim, o ato da emancipação é um ato de desconstrução total do significado do social; uma nova ordem será estabelecida no lugar da anterior. No entanto, para o autor, mesmo que haja uma ressimbolização radical no momento emancipatório, uma emancipação total (no sentido político e social) é impossível, pois a emancipação de uma estrutura leva, necessariamente, a sedimentação de outra. Aqui reside uma diferença importante: para Laclau uma estrutura será sempre substituída por outra.

$\mathrm{Na}$ visão do autor, emancipação constitui dois momentos radicais: em primeiro lugar requer uma fundação radical, e em segundo uma exclusão radical. Ou seja, apresenta um fundamento do social e ao mesmo tempo sua impossibilidade, algo que está contido nesse "elemento" fundante e algo que ele exclui. "Se o ato de emancipação é verdadeiramente radical, ele vai realmente deixar para trás tudo o que o precedeu, tem de ocorrer no nível da fundação do social" (Laclau, 2011 [1996], p. 24). O que possibilita a ideia de emancipação é a existência de algo que oprime o livre desenvolvimento (isso também serve para a ideia de liberdade). Contudo, o ato emancipatório subverte esse limite e delimita um novo, reconstruindo novos limites e um novo fundamento, precário e contingente - a emancipação é um abismo entre a desconstrução (o deslocamento) de um fundamento para a sedimentação de outro; a emancipação plena, portanto, é uma impossibilidade.

Emancipação não traz algo que apresente uma novidade em relação à estrutura existente, mas é o exato momento da falha estrutural. Portanto, a possibilidade da liberdade emerge no exato momento de contestação frente a essas estruturas, da insatisfação com a "ordem simbólica" estabelecida.

Não existe emancipação sem opressão, e não há opressão sem a presença de algo que lhe é tolhido em seu livre desenvolvimento pelas forças opressivas. Emancipação não é, nesse sentido, um ato de criação, mas ao contrário, de libertação de algo que precede o ato libertador (Laclau, 2011 [1996], p. 24).

A nova fundação não apresentará continuidade entre a estrutura anterior e a nova que se coloca em seu lugar. Contudo, como percebe-se nas palavras de Laclau, por mais que o elemento propulsor do ato emancipatório esteja contido na ordem social que a precede, a liberdade é o momento em que tal estrutura não mais significa e gera sentido para as identidades. Nas palavras do autor emancipação depende de uma estrutura, mas, por outro lado, uma nova estrutura será instituída. É no fato de que uma nova estrutura será erguida que a emancipação se torna impossível.

Isso não nos deve levar, no entanto, ao simples abandono da lógica da emancipação. Ao contrário, é jogando-se no interior do sistema de suas incompatibilidades lógicas que podemos abrir caminho para novos discursos liberadores que não mais estejam presos às antinomias e aos becos sem saída a que a noção clássica de emancipação levou (Laclau, 2011 [1996], p. 25).

Portanto, o debate em torno do momento emancipatório apresenta novas possibilidades que remetem ao entendimento do significado de liberdade. Se momentos emancipatórios plenos são impossíveis, momentos libertadores a partir de pluralidades identitárias se tornam cada vez mais uma realidade do conflito político. É entendendo o caráter deslocado de toda identidade e sua constituição a partir de relações antagônicas que se podem vislumbrar novos espaços de liberdade. 


\section{Deslocamento e antagonismo}

Foi afirmado nas seções anteriores que um discurso se constitui a partir de uma relação antagônica imersa numa complexidade formada por diversas relações antagonizadas por diversos discursos que são marcados por um vazio deslocatório. A possibilidade dessa relação e do não fechamento de um discurso e de uma identidade é marcada pela falta (falha estrutural), pelo espaço vazio que possibilita a formação de novas identidades a partir de identificações políticas (antagônicas).

Isso implica na compreensão de que o espaço do social é "formado por uma multiplicidade de práticas que não esgotam a realidade referencial e empírica dos agentes que fazem parte dela" (Laclau e Mouffe, 2015 [1985], p. 210-211). No entanto, para que o antagonismo ocorra, é necessário compreender que toda identidade é deslocada e marcada por uma falta constitutiva e, ao mesmo tempo, sempre em busca de uma certa sedimentação. Desta maneira, um discurso se constitui em oposição a outro discurso, ao seu "negativo", ao seu concorrente, de forma a negar toda substância antagonizada a partir da produção de sentidos opostos. Além disso, dentro dessa disputa discursiva, o antagonismo impossibilita o fechamento completo dos sentidos de um discurso; "[...] o antagonismo e a exclusão são constitutivos de toda identidade" (Laclau, 2011 [1996], p. 88). O antagonismo não tem um sentido objetivo, ele é a própria impossibilidade de sua construção ${ }^{11}$.

Laclau (2000 [1990], p. 180) afirma que toda positividade interna de um discurso só é possível por um exterior radical que subverte e impossibilita sua expansão e completude, ou seja, o corte antagônico. O seu negativo é a própria possibilidade de articulação interna de um discurso e a construção dessa positividade, uma positividade sempre limitada e falha em sua tentativa de completude (Laclau, 2000 [1990], p. 34). A relação com o outro é condição de qualquer identificação política (Laclau, 2000 [1990], p. 37) e, portanto, o limite antagônico marca as relações políticas constitutivas do social. "[...] o antagonismo e a exclusão são constitutivos de toda identidade” (Laclau, 2011 [1996], p. 88).

No momento da articulação, a falha da estrutura não desaparece. Isso torna possível a constituição e a organização das demandas que serão articuladas. Tal relação não se deu por uma vontade positiva, mas por uma falta constitutiva que emerge no caráter deslocado de toda identidade discursiva e que faz emergir a relação antagônica. É esta falta (falha estrutural) que torna possível a modificação das identidades envolvidas que transitarão entre elementos e momentos em diversas relações antagônicas emergentes dentro do espaço do social. O sentido de que uma identidade é sempre deslocada (Laclau, 2000 [1990], p. 59-60) é o espaço de proliferação das relações antagônicas que construirão identificações políticas que resultarão numa identidade discursiva sempre limitada, precária e contingente. Além disso, o autor afirma que o deslocamento "resulta da presença de forças antagônicas" (Laclau, 2000 [1990], p. 56-57), o que nos leva a compreender que o caráter deslocado de toda identidade é reconfigurado pelo exterior constitutivo a partir de uma falta constitutiva, ou seja, o deslocamento possibilita novas identificações a partir das relações antagônicas.

As lutas democráticas emergem num contexto marcado por uma dupla característica que pode parecer paradoxal: o campo é relativamente suturado e, ao mesmo tempo, as identidades sempre deslocadas (Laclau, 2000 [1990], p. 37) expressam seu caráter fragmentado. Com isso, o fato de o

\footnotetext{
${ }^{11}$ Uma revisão e interpretação sobre o conceito de antagonismo pode ser encontrada em Mendonça (2003a; 2012).
} 
social ser "relativamente suturado" não é o mesmo que afirmar que ele está fundado numa objetividade última, mas sim afirmar seu caráter precário. Portanto, sua precariedade e contingência indicam sua fragmentação como social e as múltiplas possibilidades de articulações discursivas, o que, por outro lado, não elimina uma possível articulação com outros discursos na formação de um discurso mais amplo que possa dividir o social em dois polos, o do populismo (Laclau, 2013 [2005]).

Mendonça (2012), tratando sobre a categoria antagonismo a partir da releitura feita por Laclau e indicando sua função no desencadeamento de um processo articulatório, afirma que "[...] sua função limita-se a isso, uma vez que, estando o corte antagônico externo ao discurso, ele não é capaz de produzir sentido nele" (Mendonça, 2012, p. 206). Decerto, um discurso não é capaz de produzir sentidos em termos positivos num outro discurso, o que não elimina sua necessidade constitutiva, tendo em vista seu caráter deslocado, da relação com o seu negativo nessa constituição. Isto significa dizer que a reestruturação de um sistema deslocado só é possível em virtude da relação antagônica. "[...] mostrar que a negatividade é constitutiva de toda identidade e que, portanto, o projeto racionalista de determinar o sentido objetivo ou positivo último dos processos sociais estava destinado ao fracasso" (Laclau, 2000 [1990], p. 20).

As forças antagônicas não são a expressão de um movimento objetivo mais profundo que englobaria a ambas, e o curso da história não pode, por tanto, expandir-se a partir da objetividade essencial de nenhuma delas. Esta última é sempre uma objetividade ameaçada por um exterior constitutivo (Laclau, 2000 [1990], p. 39).

Feitas essas ponderações, e levando em consideração as indicações de Mendonça (2012), que por sua vez baseou-se nas reflexões da carta de Alleta Norval sobre o caráter positivo na formação de uma identidade ${ }^{12}$, Laclau (2000 [1990], p. 180) afirma que a positividade interna de um discurso só é possível por um exterior radical que subverte e impossibilita sua expansão e completude, ou seja, o corte antagônico. O seu negativo é a própria possibilidade de articulação interna de um discurso e a construção dessa positividade, uma positividade sempre limitada e falha em sua tentativa de completude (Laclau, 2000 [1990], p. 34).

$\mathrm{O}$ antagonismo exerce uma função no sentido de desestabilizar e subverter as diferenças constituídas, seja dentro do discurso antagônico, seja dentro do próprio discurso antagonizado. Por isso, toda identidade será constantemente cindida, marcada pela relação entre a lógica da diferença e a lógica da equivalência. É neste trânsito, entre diferença e equivalência, constantemente deslocado, conforme o autor, que reside o momento da indecibilidade.

A realidade social não pode ser simplesmente descrita por relações preestabelecidas. Não existe uma essência que define uma identidade, pelo contrário, é a impossibilidade de se chegar a essa essência que constitui e configura as identificações resultantes dessa luta antagônica. Por isso, como busca-se demonstrar, a formação de identificações políticas parte de uma disputa política que é marcada por uma fronteira que a delimita, o que impõe um não fundamento, ou seja, a disputa política é fruto de conflitos que constituem identificações políticas que jamais serão finitas, fechadas, mas que constituem identidades enquanto articuladas em torno de um ponto nodal.

\footnotetext{
${ }^{12}$ Este debate entre Norval e Laclau é parte um dos capítulos do livro "Nuevas reflexiones sobre la revolución de nuestro tempo" (Laclau, 2000 [1990]).
} 
O exterior constitutivo na operação de uma identificação política não pode ser confundido como algo similar, mas o oposto disso. O que caracteriza o momento de uma identificação é a existência de um deslocamento no sistema em que a identidade será reconfigurada por uma nova identificação limitada e constituída a partir de uma falta que marcará a emergência do corte antagônico. É neste sentido que a sociedade é compreendida como uma impossibilidade (Laclau, 2000 [1990]), pois as relações antagônicas constituem o social que, a partir de relações de identificações possibilitadas pelo seu corte antagônico, fragmentam o espaço do social apresentando sua complexidade constituída a partir de diversas lutas, sem o reducionismo de uma luta apenas e com a formação de identidades fechadas em torno dessa luta.

Compreende-se que toda atividade política jamais será finita, pois é constituída por uma falta, por uma falha estrutural. Entende-se, assim, que toda identidade é deslocada na medida em que depende de um exterior constitutivo que, ao mesmo tempo em que a nega, é sua condição de possibilidade. Mas isto mesmo significa que os efeitos do deslocamento terão de ser contraditórios. Se por um lado eles ameaçam as identidades, por outro estão na base da constituição de novas identidades (Laclau, 2000 [1990], p. 55).

\section{O sentido (conceito) de liberdade na teoria do discurso laclauniana}

Até este momento foram explicados e enfatizados quatro aspectos balizares que permeiam a teoria do discurso laclauniana e que abrem caminho para um melhor entendimento do sentido (conceito) de liberdade no próprio âmbito da teoria, bem como num debate com outros sentidos de liberdade. $\mathrm{O}$ primeiro ponto foi o de compreender que tudo no social se constitui de forma simbólica, e a organização desse processo é chamado discurso. O segundo ponto é o de que toda identidade ou estrutura é constituída por uma falta, uma falha estrutural que emerge na prática política e que jamais será contemplada em sua totalidade. O terceiro ponto é o de que toda relação política se constitui por meio de uma relação de negatividade, de conflito; a relação antagônica assume um papel central na formação e organização de identidades políticas. Por fim, o quarto ponto é identificado na impossibilidade da emancipação ${ }^{13}$.

Entende-se que o caráter deslocado de toda identidade impossibilita a eternidade de uma identidade e que a relação antagônica impede a formação positiva de qualquer identidade. Deste modo, primeiramente é importante compreender que a liberdade só é possível tendo em vista o caráter deslocado de toda identidade e a impossibilidade de completude (a falta estrutural/falta constitutiva). Em segundo, há liberdade porque nenhuma identidade se constitui de forma positiva, mas a partir de relações antagônicas. Em terceiro, nenhuma identidade assume o locus da liberdade e sua eterna posição estrutural. Em quarto, nenhuma identidade atingirá a liberdade como algo objetivo, com algo a se emancipar.

Liberdade, no limite, é a inexistência de estrutura (desestruturação). Neste mesmo sentido, liberdade é ausência de constrangimentos. Liberdade para Laclau (2000 [1990], p. 59) é ausência de determinação. Por outro lado, afirmar isso não é o mesmo que dizer que liberdade é a total falta de constrangimentos. Pelo contrário, é a existência desses constrangimentos que possibilitam a liberdade. Isso nos leva a um paradoxo: liberdade é, ao mesmo tempo, um ato libertador e escravizante

\footnotetext{
${ }^{13}$ Sobre outros aspectos relacionados à emancipação no sentido atribuído por Laclau e outros desdobramentos além dos previstos neste texto, ver Mendonça (2008).
} 
(desestruturação e reestruturação). Além disso, conforme o autor (Laclau, 2000 [1990], p. 61) há liberdade porque a sociedade não se constitui de forma objetiva; a sociedade é fragmentada e se sedimenta a partir de diversas disputas antagônicas.

Por isso, o deslocamento é a fonte da liberdade (Laclau, 2000 [1990], p. 96), ou seja, o caráter deslocado e incompleto de toda identidade possibilita momentos de liberdade na tentativa de preencher essa falta impossível de ser sanada. A liberdade, assim, emerge a partir de relações antagônicas possibilitadas pelo caráter deslocado de toda identidade (estrutura). Portanto, o fato de que toda identidade ser deslocada e que todas as relações se constituam a partir de processos antagônicos, indica que a liberdade só pode existir no deslocamento e relacionada com seu limite, o antagônico.

É neste campo, da impossibilidade de uma determinada identidade se constituir de forma total, que a liberdade opera. A liberdade está ligada diretamente ao momento da falha estrutural, ou seja, uma identidade para se constituir como identidade através de um processo de identificação depende, ao mesmo tempo, da estrutura e da falha da estrutura. Esse movimento que institui um processo para identificar aquilo que lhe falta, levará a uma nova sedimentação social - uma nova delimitação estrutural.

Essa situação contraditória é expressa na indecibilidade entre a internalidade e a externalidade do opressor em relação ao oprimido: ser oprimido é parte da minha identidade como um sujeito lutando por emancipação. Sem a presença do opressor, minha identidade seria diferente. Sua constituição requer e simultaneamente rejeita a presença do outro (Laclau, 2011 [1996], p. 44).

O momento da liberdade não é um momento eterno, mas um momento limitado entre a desestruturação e reestruturação. Em outras palavras, esse processo dará um novo sentido ao tecido social envolvido (identidade ou estrutura), uma nova sedimentação formada por elementos precários e contingentes marcados pelo seu caráter deslocado e pela relação antagônica que emergirá a partir de novas relações.

Deste modo, como afirma Norval num momento de reflexão sobre as afirmações feitas por Laclau, "a liberdade não possui conteúdo positivo, mas é uma mera possibilidade" (Howarth e Norval in Laclau, 2011 [1996], p. 45).

A liberdade é tão libertadora quanto escravizante, revigorante e traumática, capacitadora e destrutiva. Numa sociedade fragmentada e heterogênea, os espaços de liberdade certamente aumentam. Mas esse não é um fenômeno uniformemente positivo, porque instala naquele espaço a ambiguidade da liberdade. Como resultado, surge a possibilidade de tentativas mais radicais de renunciar à liberdade do que aquelas que conhecemos do passado. Se a liberdade e o deslocamento caminham juntos, é no terreno de uma liberdade generalizada que experiências como as do totalitarismo contemporâneo tornam-se possíveis (Laclau, 2011 [1996], p. 46).

Por isso a ideia da liberdade ser tão libertadora quanto escravizante, ela nunca será completa, como nenhuma identidade. Ela sempre será um vazio a ser preenchido que, consequentemente, dará origem a outro vazio, que logo se tornará estruturado novamente. Como destaca Norval, "a falha da 
estrutura em constituir plenamente o sujeito força o sujeito a ser sujeito, a tomar uma decisão, a agir, a se identificar de novo" (Howarth e Norval in Laclau, 2011 [1996], p. 45). É por isso que o momento da liberdade é visto como uma nova reestruturação, e não uma ação racional de emancipação como supunham os teóricos do marxismo clássico.

Se os antagonismos são constitutivos do social, é a própria ideia de liberdade que institui o seu não fundamento, a sua precariedade e contingencia. Quando se lida com dois polos que dividem o social em dois, isso fica mais claro, mas quando trata-se de pluralidades no espaço do social dividindo tal espaço em inúmeras disputas, a compreensão requer um esforço maior, o que é o caminho para a democracia radical.

Essa precariedade e incompletude das fronteiras que constituem a divisão do social estão na raiz da possibilidade contemporânea de uma autonomização das lutas sociais - os chamados novos movimentos sociais -, em vez de subordiná-las a uma fronteira una que seria a única fonte de divisão do social (Laclau, 2011 [1996], p. $44)$.

Laclau (2011 [1996], p. 46), ao abordar diretamente a relação de liberdade numa sociedade democrática, afirma que a "liberdade/não liberdade" pode ser percebida a partir da negociação existente nessa estrutura e, com isso, se ter uma definição de suas possibilidades e limites. Os espaços de liberdade previstos num modelo democrático são entendidos como possibilidades de articulações discursivas que constituirão identificações políticas e, com isso, identidades (novas estruturas discursivas). Então, em modelos democráticos (e mais ainda num modelo radical de democracia) os espaços de liberdade são proliferados, o que prolifera ainda mais as pluralidades das identidades nos processos de identificações. "Este é o ponto em que os discursos potencialmente liberatórios de nossa época pós-moderna têm de ser iniciados. Podemos talvez dizer que hoje estamos no fim da emancipação e no início da liberdade” (Laclau, 2011 [1996], p. 44-45).

A citação acima apresenta uma crítica à visão marxista clássica a qual entedia ser possível um processo emancipatório total. Contrariando isso, a partir da pluralização do social e o fim da dicotomização entre dois polos (burguês contra o proletariado), Laclau entende ser possível a pluralização de identidades, o que permite novas formas de liberdade. Por isso, a afirmação de Laclau de que estamos no fim da emancipação e no início da liberdade ilumina uma definição de democracia - em seu sentido radical - na qual a possibilidade da liberdade pode ser identificada a partir da falta que constitui e articula as identidades por meio de processos antagônicos. "O que entendo por liberdade não é uma plenitude positiva e sem nuances, mas algo essencialmente ambíguo" (Laclau, 2011 [1996], p. 45). A liberdade plena é uma impossibilidade e, deste modo, o momento da liberdade não é um momento para todo o sempre.

Em se tratando de um contexto democrático marcado pela pluralidade de identidades, as disputas antagônicas como contestação dessa ordem serão resultantes de um ato libertador das identidades envolvidas nesse processo de identificação. Nesse processo contínuo, as identidades envolvidas ao processo de identificação já se encontrarão presas a uma nova estrutura fruto dessa articulação, ou seja, marcando o fim deste momento de liberdade.

Quando se trata de uma política democrática, a incompletude das identidades e provisoriedade dos fundamentos construídos a partir de disputas antagônicas constituem o tecido do social. 
[...] uma sucessão de identidades finitas e particulares que tentam assumir tarefas universais que as ultrapassam, mas que, em decorrência, nunca são capazes de ocultar inteiramente a distância entre tarefa e identidade - e podem sempre ser substituídas por grupos alternativos (Laclau, 2011 [1996], p. 42).

Com isso, se hora uma identidades poderá estar articulada com um discurso e hora com outro, constituindo, assim, a relação entre "inclusão"/“exclusão", o não fundamento do social e a pluralidade de identidades e relações marcam a possibilidade do momento da liberdade. Um bom exemplo para iluminar o que foi colocado até este momento é a relação discursiva entre os atores (aqui no sentido de sujeitos do discurso) ligados ao movimento ecológico e os atores ligados ao plantio de arroz, constituindo novos sujeitos, os "ambientalistas", contra a política de reflorestamento realizada no Estado do Rio Grande do Sul, assumindo a posição de sujeito "desenvolvimentista" (Vieira Júnior, 2010). Para além dos achados de Vieira Júnior, o propósito aqui é o de apontar que essa relação discursiva emerge num contexto democrático em que nenhuma identidade está presa a priori a nenhum fundamento que estruture sua própria identidade. Ambientalistas, no sentido atribuído pelo autor, formam uma identidade num processo articulatório em que se pode apontar duas identidades anteriores: os ecologistas e os arrozeiros. Fora desse contexto específico, essas identidades são historicamente antagônicas. A articulação entre elas dá origem a uma nova identidade. Posterior a este contexto, elas tornaram as suas posições, de relação antagônica. Futuramente, não há como prever o que ocorrerá. O fato é o de que os processos de identificação recorrem.

A liberdade emerge na falta (deslocamento), marcada pelo seu corte antagônico. Portanto, liberdade é um momento em que se dá a articulação e a formação de uma identidade. Liberdade não tem uma positividade, não pertence a uma identidade específica e tampouco é definida por uma estrutura. Liberdade é um instante entre a desestruturação e a reestruturação, por isso ela não pertence a nenhuma estrutura, ela só aparece no momento em que a estrutura falha. Tal perspectiva oxigena tanto o debate em torno do que é liberdade, como possibilita a ampliação da compreensão da liberdade em modelos democráticos, aqui pensados a partir do modelo radical de democracia e sua dimensão de pluralidade.

\section{Considerações Finais}

As transformações ocorridas entre o século XX e início do século XXI mostram que modelos democráticos se tornam cada vez mais permeáveis a diferenças discursivas e possibilitam, com isso, novos processos articulatórios dessas diferenças na produção de renovados processos de identificações na constituição de sujeitos sociais (discursivos) descentrados e sem fundamentação última. O trabalhador, hoje, não é mais visto somente como "mão-de-obra" de um determinado "local" ou esfera, ou mesmo como simples classe homogenia e unificada em torno dessa identidade (identificação). Além de trabalhador, nas democracias contemporâneas ele passa a ser visto como consumidor - em relação ao mercado -, como cliente - em relação alguma forma de prestação de serviço -, como pai ou mãe - numa relação familiar -, e entre tantas outras formas. E isso não ocorre a partir de uma simples separação de posição, mas a partir de uma relação múltipla entre todos esses processos identitários envolvidos, dependendo do contexto. Isso quer dizer que não há uma troca de 
uma identidade por outra - como emancipação -, mas um processo contínuo de formações de renovas identidades. Num modelo democrático, esses processos se ampliam. Diferente de um modelo repressivo, em que esses processos são limitados por alguma estrutura autoritária.

Se identidades se tornam cada vez mais complexas em função de sua polissemia, é a liberdade existente no processo articulatório dessa polissemia que ocorrem em processos de identificações que evidenciam o status de um modelo radical de democracia. Sem querer adentrar em outro terreno, afirma-se que para Laclau uma liberdade democrática só pode ser classificada dessa forma quando evidenciada os processos de articulação entre identidades que se libertam de suas estruturas tidas socialmente como fixadas. O próprio exemplo do(s) movimento(s) feminismo(s) pode ser compreendido a partir do que o autor entende como liberdade. Enquanto mulher existia determinadas faltas, logo, enquanto ativista, por exemplo, outras faltas emergem, e emergem produzindo novos processos de identificação.

Democracia radical e liberdade, a partir do exposto neste texto, estão ligadas diretamente com a ideia de pluralidade do social. A pluralidade se mostra em momentos democráticos que evidenciam $o$ ato libertador de identidades em constantes e renovados processos de identificação. A liberdade num sentido mais amplo, e a liberdade num modelo pensado como radical de democracia, assim, é quando se verifica a possibilidade de articulações discursivas entre identidades múltiplas e múltiplas identidades.

\section{Referências}

DERRIDA, Jacques. A escritura e a diferença. São Paulo: Editora Perspectiva, 2014 [1971].

FOUCAULT, Michel. A Arqueologia do saber. Rio de Janeiro: Editora Forense Universitária, 2013a [1969].

. A ordem do discurso. São Paulo: Loyola, 2013b [1970].

HOWARTH, David; NORVAL, Aletta. Da emancipação à liberdade. In: LACLAU, Ernesto. Emancipação e Diferença. Rio de Janeiro: EDUERJ, 2011 [1996].

LACAN, Jacques. O seminário, livro 11: os quatro conceitos fundamentais da psicanálise. Rio de Janeiro: Jorge Zahar, 2008 [1973].

LACLAU, Ernesto. A Razão Populista. São Paulo: Três Estrelas, 2013 [2005].

. Emancipação e Diferença. Rio de Janeiro: EDUERJ, 2011 [1996]. 2000 [1990].

. Nuevas reflexiones sobre la revolución de nuestro tiempo. Buenos Aires: Nueva Visión,

. Os novos movimentos sociais e a pluralidade do social. Revista Brasileira de Ciências Sociais, v. 1, n. 2, p. 41-47, 1986.

. Política e Ideologia na Teoria Marxista. Rio de Janeiro: Paz e Terra, 1978 [1977].

LACLAU, Ernesto; MOUFFE, Chantal. Hegemonia e Estratégia Socialista: por uma política democrática radical. São Paulo/Brasília: Intermeios/CNPq, 2015 [1985]. 
MARCHART, Oliver. El pensamiento político posfundacional: la diferencia política em Nancy, Lefort, Badiou e Laclau. Buenos Aires: Fondo de Cultura Económica, 2009 [2007].

MARTÍNEZ, Horacio. De enemigos a adversarios: la transformación del concepto de "lo político" de Carl Schimitt por Chantal Mouffe. Revista Andamios, v.11, n. 24, p. 83-102, 2014.

MARX, Karl; ENGELS, Friedrich. A ideologia alemã. São Paulo: Martins Fontes, 1998 [1946].

MENDONÇA, Daniel. Antagonismo como identificação política. RBCP, v. 1, n. 9, p. 205-228, 2012.

. Teorizando o agonismo: crítica a um modelo incompleto. Revista Sociedade e Estado, v. 25, n. 3, p. 479-497, 2010.

. A impossibilidade da emancipação: notas a partir da teoria do discurso. In: RODRIGUES, Léo; MENDONÇA, Daniel (Orgs.). Pós-Estruturalismo e Teoria do discurso: Em torno de Ernesto Laclau. Porto Alegre: EdiPUCRS, 2008.

. A teoria da hegemonia de Ernesto Laclau e a análise política brasileira. Cências Sociais Unisinos, v. 43, n. 3, p. 249-258, 2007.

. A noção de antagonismo na ciência política contemporânea: uma analise a partir da perspectiva da teoria do discurso. Revista Sociologia Política, v. 1, n. 20, p. 135-145, 2003a.

. A teoria do discurso de Laclau e Mouffe: em direção a noção de significante vazio. Revista Barbarói, v. 1, n. 18, p. 55-71, 2003 b.

MENDONÇA, Daniel; LINHARES, Bianca; BARROS, Sebastián. O fundamento como "fundamento ausente" nas ciências sociais: Heidegger, Derrida e Laclau. Revista Sociologias, v. 1, n. 41, p. 164-194, 2016.

MENDONÇA, Daniel; RODRIGUES, Léo. Do estruturalismo ao pós-estruturalismo: entre fundamentar e desfundamentar. In: MENDONÇA, Daniel de; RODRIGUES, Léo (Orgs.). PósEstruturalismo e Teoria do Discurso: em torno de Ernesto Laclau. Porto Alegre: EDPUCRS, 2014.

MOTTA, Luiz Eduardo; SERRA, Carlos Henrique Aguiar. A ideologia em Althusser e Lalcau: diálogos (im)pertinentes. Revista Sociologia e Política, v. 22, n. 50, p. 125-148, 2014.

MOUFFE, Chantal. Sobre o politico. São Paulo: Martins Fontes, 2015 [2005].

. Agonistics: thinking the world politically. London: Verso, 2013.

2005.

. Por um modelo agonístico de democracia. Revista Sociologia Política, n. 25, p.11-23, . La paradoja democrática. Barcelona: Gedisa, 2003 [2000].

. O regresso do político. Lisboa: Gradiva, 1999 [1996].

SCHMITT, Carl. O conceito do político: Teoria do Partisan. Belo Horizonte: Del Rey, 2009 [1932].

STAVRAKAKIS, Yannis. Lacan y lo político. Buenos Aires: Prometeu Libros, 2007 [1999].

VIEIRA JUNIOR, Roberto. Ambientalistas e Desenvolvimentistas: aplicando a teoria do discurso. Pelotas: Gráfica Universitária/UFPEL, 2010.

WILLIANS, James. Pós-estruturalismo. Rio de Janeiro: Vozes, 2012 [2005]. 


\author{
Artigo recebido em: Setembro/2018 \\ Artigo aceito em: Junho/2019
}

\begin{abstract}
Felipe Corral de Freitas (felipecorrall@gmail.com) realiza estágio pós-doutoral no Programa de Pós-Graduação em Ciência Política da Universidade Federal Pelotas (UFPel). Doutor pelo Programa de Pós-Graduação em Ciência Política da Universidade de Brasília (UnB).
\end{abstract}

\title{
O Sentido (Conceito) de Liberdade na Teoria do Discurso de Ernesto Laclau
}

\begin{abstract}
Resumo. De origem marxista, a teoria do discurso laclauniana tem como objetivos ampliar e redefinir a compreensão da atividade política, bem como redimensionar as relações de conflitos que configuram as relações sociais para além da polarização entre proletariado e burguês, se colocando numa linha pós-marxista. Influenciado pelo pós-estruturalismo, Laclau entende que não existe nenhum fundamento capaz de definir a estruturalidade última de uma identidade política e, por isso, sedimentar um discurso para todo o sempre. É nesta esteira que Laclau desconstrói o entendimento de emancipação segundo a teoria marxista e desenvolve uma perspectiva de liberdade mais complexa e menos restritiva em termos de teoria política. Então, apresentar o que constitui liberdade, seu lugar e seu momento a partir da teoria do discurso de Laclau designa o objetivo deste artigo.
\end{abstract}

Palavras-chave: Teoria do Discurso; Emancipação; Liberdade; Deslocamento; Antagonismo.

\section{The Sense (Meaning) of Freedom in Ernesto Laclau's Discourse Theory}

\begin{abstract}
Marxist theory has as its objectives to broaden and redefine the understanding of political activity, as well as to re-dimension the relations of conflicts that shape social relations beyond the polarization between proletariat and bourgeois, placing itself in a post-Marxist line. Influenced by post-structuralism, Laclau understands that there is no foundation capable of defining the ultimate structure of a political identity and, therefore, sedimenting a discourse forever and ever. It is in this wake that Laclau deconstructs the understanding of emancipation according to Marxist theory and develops a perspective of freedom more complex and less restrictive in terms of political theory. Then, presenting what constitutes freedom, its place and its moment from the theory of discourse of Laclau designates the objective of this article.
\end{abstract}

Keywords: Discourse Theory; Emancipation; Freedom; Displacement; Antagonism. 